\title{
Ocular Signs in Alport's Syndrome
}

\author{
S. M. THOMPSON ${ }^{1}$, J. P. DEADY ${ }^{1}$, H. E. WILLSHAW ${ }^{1}$ and R. H. R. WHITE ${ }^{2}$ \\ Birmingham
}

\begin{abstract}
Summary
The eyes of sixty one patients with Alport's syndrome or its variant, and of 25 unaffected relatives, were examined. Details of ocular signs associated with Alport's syndrome are presented and related to renal prognosis and family history.
\end{abstract}

Alport's syndrome comprises hereditary nephritis and perceptive deafness. Electron microscopy of the renal glomerular basement membrane reveals characteristic changes consisting mainly of irregular thickening, with a lamellated appearance of the lamina densa., ${ }^{1,2}$ The inheritance of the syndrome is unclear, but affected males are more likely to be deaf, and develop renal failure more frequently than affected females. Females usually have no more than asymptomatic microscopic haematuria. It is recognised ${ }^{3}$ that the hearing loss in Alport's syndrome usually starts between the ages of five and ten years, but may appear later. Deafness is uncommon in affected females. ${ }^{3}$

Characterisation of the renal glomerular ultrastructural abnormalities has helped to define a group of patients who have an identical form of nephritis but in whom deafness never develops, even in males. They have been called 'Alport variants'. ${ }^{3}$

The incidence of ocular changes in Alport's syndrome has been reported as between 11 per cent and 43 per cent. ${ }^{4,5,6}$ We examined a series of 62 patients with Alport's syndrome and its variants, as well as 25 unaffected relatives, and report the incidence, nature, and implications of the ocular changes.

\section{Patients \\ Two groups of patients were examined.}

Group 1: patients with typical Alport's Syndrome These patients had haematuria with or without proteinuria and renal failure, and a personal or family history of sensorineural deafness shown on audiometry. Either they or a first degree relative had a typical renal biopsy appearance with more than 50 per cent of the renal glomerular basement membrane affected by the characteristic changes.

There were 42 people in this group ( 21 males, 21 females). Thirty had positive biopsies and 11, all mothers of biopsy-positive children, were not themselves biopsied. One affected boy refused biopsy but had a biopsy-positive brother.

The age range was 5 to 56 years (mean 22.5 years).

Tables I and II show the renal function, sex, age and aural status of the patients in this group.

The 42 individuals belonged to 18 families, and 20 unaffected relatives were also examined.

Group 2: Alport variants

These patients differed from the typical Alport's

\footnotetext{
${ }^{1}$ Department of Ophthalmology.

2 Department of Nephrology.

From Children's Hospital, Birmingham.

Correspondence to H. E. Willshaw, FRCS, Children's Hospital, Ladywood Middleway, Birmingham.
} 
Table I Group 1 patients with heamaturialmild proteinuria

\begin{tabular}{ccccc}
\hline Sex & $\begin{array}{c}\text { Under 10 } \\
\text { not deaf }\end{array}$ & $\begin{array}{c}\text { Under 10 } \\
\text { deaf }\end{array}$ & $\begin{array}{c}\text { Over 10 } \\
\text { not deaf }\end{array}$ & $\begin{array}{c}\text { Over 10 } \\
\text { deaf }\end{array}$ \\
\hline $\mathrm{M}$ & 1 & 2 & 0 & 10 \\
$\mathrm{~F}$ & 1 & 0 & 17 & 0 \\
\hline
\end{tabular}

Table II Group 1 patients with heavy proteinurial chronic renal failure

\begin{tabular}{ccccc}
\hline Sex & $\begin{array}{c}\text { Under 10 } \\
\text { not deaf }\end{array}$ & $\begin{array}{c}\text { Under 10 } \\
\text { deaf }\end{array}$ & $\begin{array}{c}\text { Over 10 } \\
\text { not deaf }\end{array}$ & $\begin{array}{c}\text { Over 10 } \\
\text { deaf }\end{array}$ \\
\hline $\mathrm{M}$ & 0 & 0 & 0 & 9 \\
$\mathrm{~F}$ & 0 & 0 & 1 & 1 \\
\hline
\end{tabular}

group only in that they had no personal or family history of deafness, but each family contained at least one biopsy-positive patient.

There were 19 people in this group ( 8 males, 4 under the age of ten, and 11 females, all over the age of ten). Eleven children had the typical changes of Alport's syndrome on renal biopsy. Seven women were not biopsied but were the haematuric mothers of children with positive biopsies. One woman, the mother of a girl with a positive biopsy, was in chronic renal failure. All the other patients had good renal function.

The age range was 5 to 42 years (mean 21.4 years).

The 19 individuals belonged to 11 families, and five unaffected relatives were also examined.

\section{Method}

After documentation of a full family and clinical history, each patient underwent an ophthalmological assessment including visual acuity, stereo acuity, slit-lamp examination, and fundus examination through dilated pupils using direct and indirect ophthalmoscopy. Most abnormalities were photographed.

Chi-square and two-tailed Fisher's exact tests were used for statistical analysis.

\section{Results \\ Ocular signs}

Ten (24 per cent) of the patients with typical Alport's syndrome showed significant ocular changes (Table III). One boy's posterior subcapsular lens opacities may be attributable to the long-term steroids he has taken since his renal transplant. Excluding this boy, the incidence of ocular involvement is 21.4 per cent. Two patients under 21 had arcus juvenilis. Two young patients had bilateral posterior corneal changes affecting either the endothelium or Descemet's membrane. The 'string of pearls' appearance (Fig. 1) was compatible with descriptions of posterior polymorphous dystrophy of the cornea, which has previously been described in association with this syndrome. ${ }^{7}$ One boy had early anterior lenticonus visible as an 'oil droplet' on retroillumination, and his vision was $6 / 9$ in

Table III Ocular signs in 10 patients with Alport's syndrome

\begin{tabular}{|c|c|c|c|c|c|}
\hline No. & Sex & Age & Deaf & Renal Status & Ocular signs \\
\hline 1 & $\mathbf{M}$ & 6 & - & Haematuria & $\begin{array}{l}\text { Posterior polymorphous } \\
\text { dystrophy }\end{array}$ \\
\hline 2 & M & 14 & + & Mild proteinuria & $\begin{array}{l}\text { Posterior polymorphous } \\
\text { dystrophy }\end{array}$ \\
\hline 3 & $\mathbf{M}$ & 15 & + & Mild proteinuria & Perimacular flecks \\
\hline 4 & $\mathbf{M}$ & 18 & + & $\mathrm{CRF}$-dialysis & $\begin{array}{l}\text { Arcus juvenilis anterior } \\
\text { lenticonus }\end{array}$ \\
\hline 5 & $\mathbf{M}$ & 20 & + & CRF_-dialysis & Perimacular flecks \\
\hline 6 & $\mathbf{M}$ & 21 & + & $\mathrm{CRF}$-transplant & $\begin{array}{l}\text { Posterior subcapsular lens } \\
\text { opacities }\end{array}$ \\
\hline 7 & M & 30 & + & CRF_dialysis & Arcus juvenilis \\
\hline 8 & $\mathrm{~F}$ & 31 & - & Haematuria & Macular flecks \\
\hline 9 & $\mathrm{~F}$ & 33 & + & $\mathrm{CRF}$-transplant & $\begin{array}{l}\text { Anterior lenticonus posterior } \\
\text { subcapsular lens opacities }\end{array}$ \\
\hline 10 & $\mathrm{~F}$ & 36 & - & Haematuria & $\begin{array}{l}\text { Flecks above upper temporal } \\
\text { vessels }(R)\end{array}$ \\
\hline
\end{tabular}

$\mathrm{CRF}=$ Chronic renal failure 


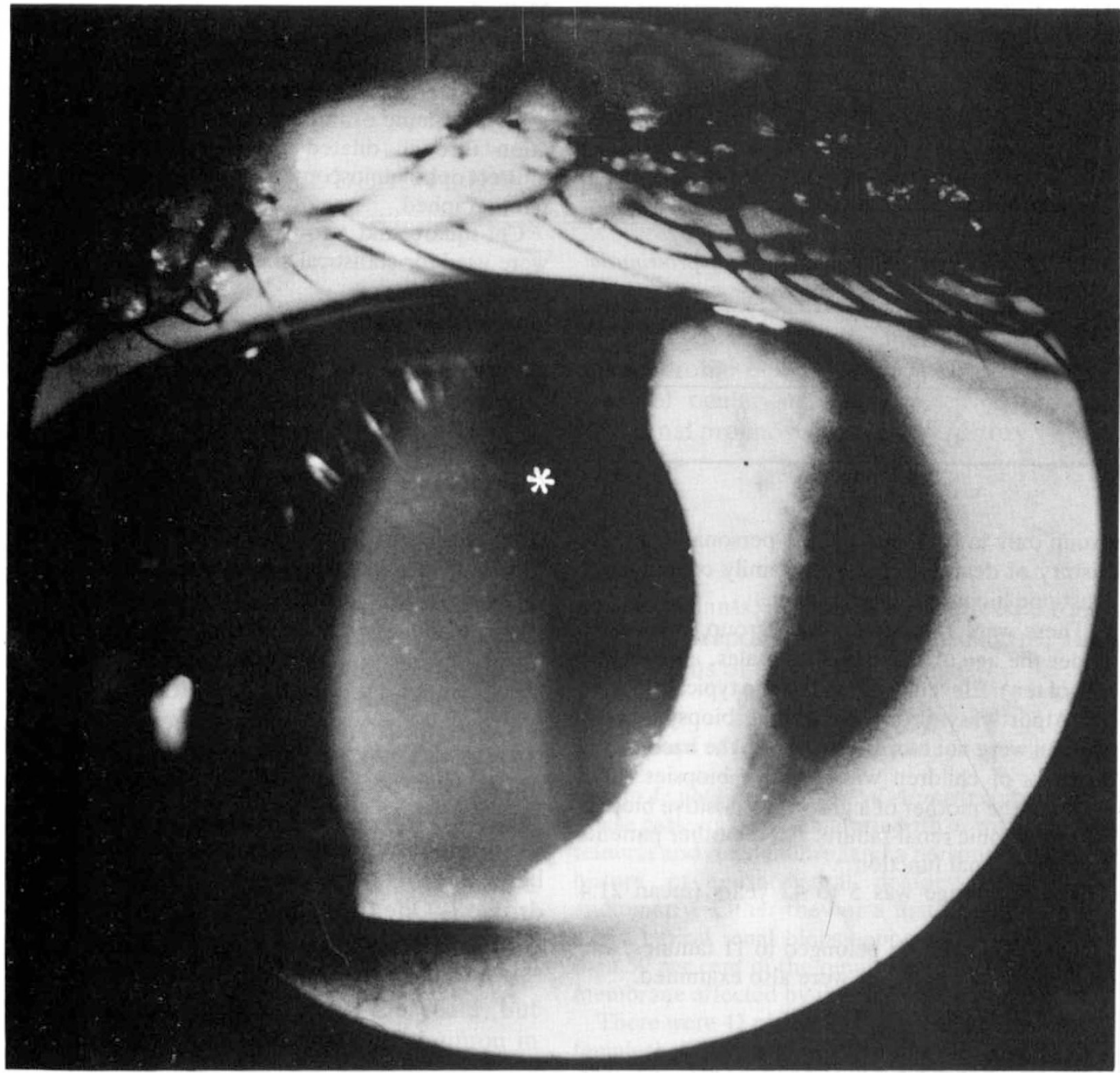

Fig. 1. Posterior polymorphous dystrophy of the cornea.

each eye. The other patient with anterior lenticonus (Fig. 2) had corrected visions of $6 / 18$ right, $6 / 24$ left. She is in chronic renal failure and is the only deaf female in the series. Three patients had the perimacular flecks reported to be characteristic of Alport's syndrome, ${ }^{5,8}$ (Fig. 3), and one had similar salt granule flecks outside the temporal arcades.

Table IV shows the relationship of the presence of ocular signs to age, sex, deafness and renal function. Those with eye changes were not significantly older than those without. There was no significant correlation between the presence of eye signs and sex or deafness (chi-square test). However, there was a significant association between the presence of eye signs and the presence of heavy proteinuria or chronic renal failure $(p=0.04$, two-tailed Fisher's exact test).

None of the Alport variant patients nor any of the unaffected relatives showed significant eye changes.

\section{Family studies}

The 42 patients with typical Alport's syndrome came from 18 families. Forty people from 16 families had positive family histories. Of those who did not, one was adopted. In 13 


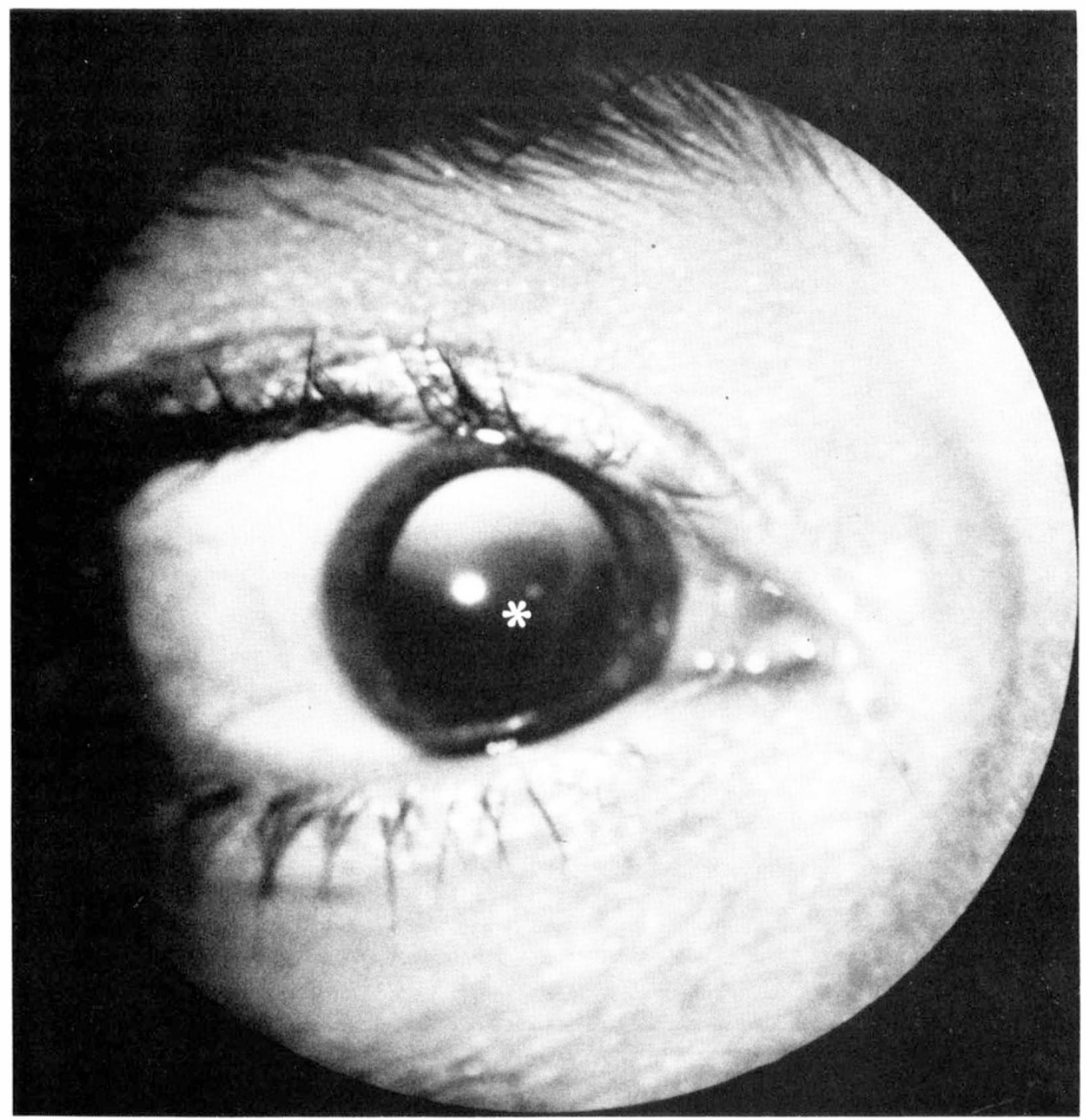

Fig. 2. Anterior lenticonus.

of the 16 families with positive histories, $\mathrm{X}$-linked inheritance was suggested by the fact that the mother of biopsy-positive children had haematuria. In another family the patient's cousin (his mother's sister's son) had chronic renal failure and deafness. In a further family the mother's urine was not tested, and in the sixteenth family only the two siblings were affected. One affected male had an unaffected son and daughter (Fig. 4).

There did not seem to be a familial inci- dence of ocular signs. Although patients 7 and 8 (Table III and Fig. 4) were brother and sister, and patients 5 and 6 (Table III) were son and mother, their eye signs differed in type.

The 19 Alport variant patients came from 11 families. Seventeen individuals had positive family histories, and one other was adopted. Of the nine sets of siblings and individuals with positive family histories, eight had mothers with haematuria, and one a mother in chronic renal failure. 


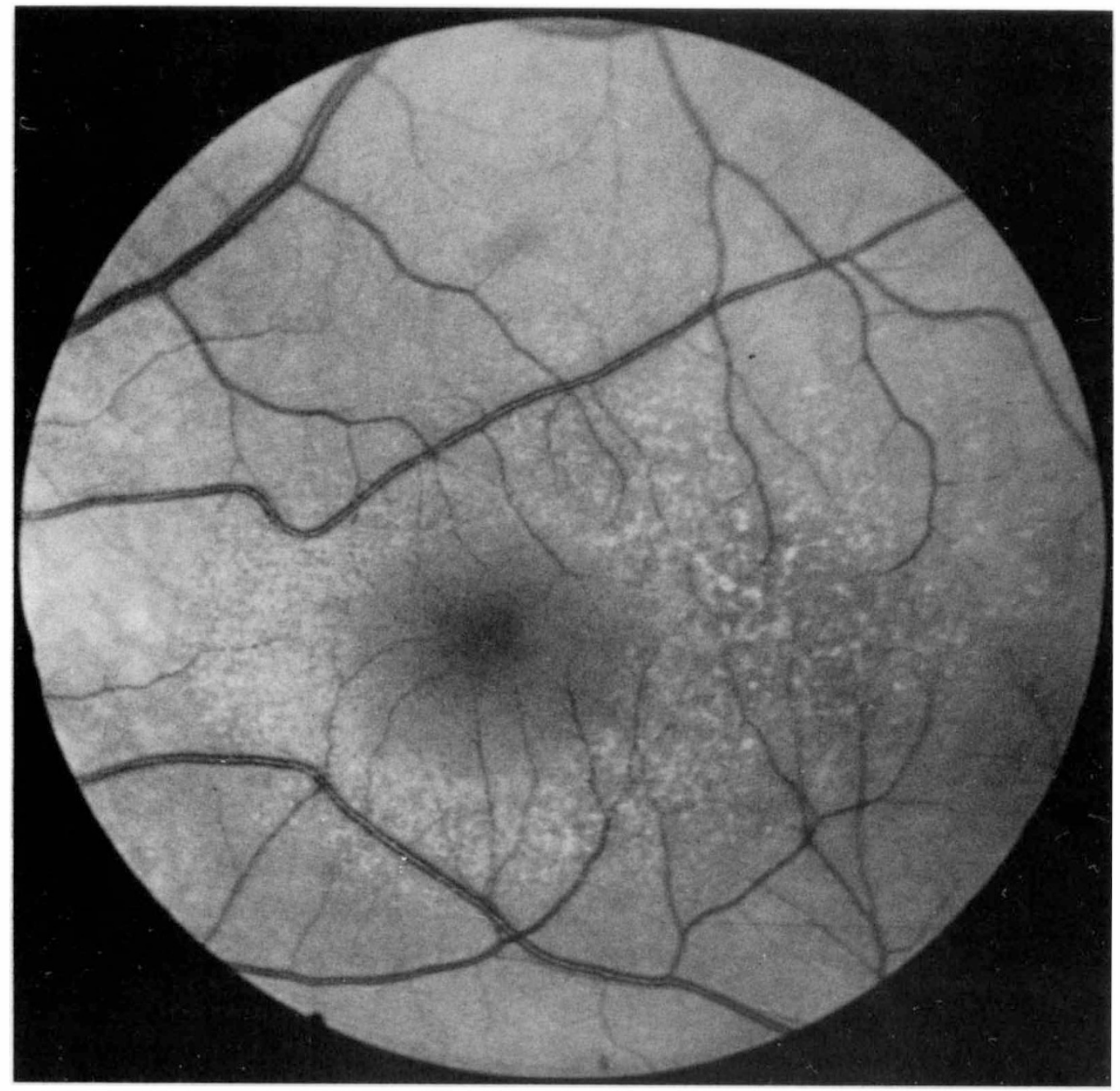

Fig. 3. Perimacular flecks.

\section{Discussion}

In examining this large series of people with Alport's syndrome and its variants, as well as their relatives, we had 3 objectives:

(1) To describe the nature and incidence of ocular changes in the syndrome and its variants.

(2) To relate the ocular changes to renal prognosis.

(3) To see whether ocular changes in the relatives of patients could clarify the inheritance of the disease.

Ocular changes in Alport's syndrome

Ocular changes in association with Alport's syndrome were first reported in $1956 .{ }^{9}$ There have been many individual reports of associated ocular signs such as spherophakia and cataracts, ${ }^{9}$ pigment dispersion syndrome, ${ }^{10}$ optic disc drusen, anisocoria, iris atrophy, iris heterochromia ${ }^{11}$ and posterior polymorphous dystrophy of the cornea. ${ }^{7}$ However, Govan ${ }^{11}$ suggests that the ocular manifestations specific to this syndrome are anterior lenticonus, perimacular and retinal flecks and possibly arcus juvenilis. We found examples of all the latter signs except retinal flecks in our affected patients, and in addition posterior polymorphous dystrophy in two.

Although the numbers are small, we sug- 
Table IV Eye signs and age, sex, deafness and renal function

\begin{tabular}{lccccc}
\hline & No & Over 10 & Male & Deaf & $\begin{array}{c}\text { Heavy } \\
\text { proteinuria/CRF }\end{array}$ \\
\hline Eye signs & 10 & $9(90 \%)$ & $7(70 \%)$ & $7(70 \%)$ & $5(50 \%)$ \\
No eye signs & 32 & $29(90 \%)$ & $14(44 \%)$ & $15(47 \%)$ & $4(12.5 \%)$ \\
Significance & & NS & NS & NS & S: $\mathrm{p}=0.04$ \\
\hline
\end{tabular}

NS: Not significant (Chi-square test).

S: Significant (Fisher's exact test).

gest that posterior polymorphous dystrophy is brane) as well as endothelial abnormalities. ${ }^{12}$ genuinely associated with Alport's syndrome. Anterior lenticonus is associated with thinHistologically, posterior polymorphous dys- ning of the anterior lens capsule ${ }^{13}$ and theretrophy is associated with thickening of fore possibly with a defect of lens epithelial Descemet's membrane (a basement mem- basement membrane. The perimacular flecks

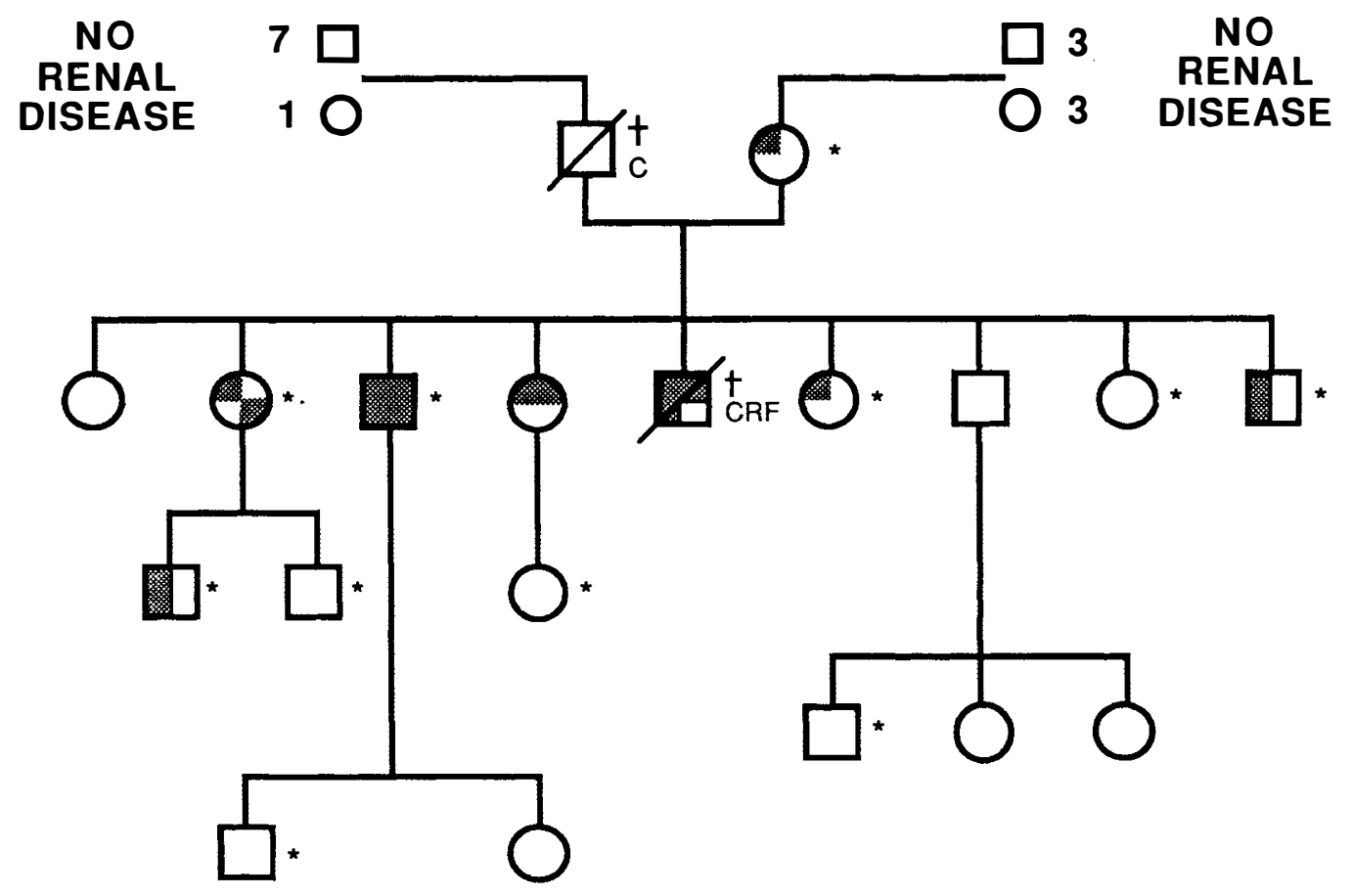

hale

Fig. 4. Family tree of an Alport family. 
seem to be at the level of the retinal internal limiting membrane, which is also a basement membrane, and the mid-peripheral retinal flecks have been thought to be associated with the pigment epithelium and Bruch's membrane. ${ }^{14}$

As the renal defect is associated with abnormalities of the glomeruler basement membrane, it is possible that all the manifestations of Alport's syndrome are due to defective basement membranes. ${ }^{15,16}$ To the best of our knowledge, there have been no recent ultrastructural or biochemical studies of ocular basement membranes in this syndrome. As Govan ${ }^{11}$ has said, much may be learned from anterior lens capsules or whole eyes obtained from affected patients.

\section{Ocular signs and prognosis}

Our finding that ocular signs are significantly linked to poor renal function agrees with that of Perrin et al. ${ }^{5}$ who were studying patients with perimacular flecks. They also found a significant correlation between perimacular flecks and deafness, and male sex, which we have not confirmed. Our findings suggest that the occurrence of eye changes is a pointer to the eventual development of renal failure. Of our patients with eye signs all except three had mild proteinuria, which heralds renal failure, or were in chronic renal failure. One of the remaining patients was a boy aged six who would not be expected to develop poor renal function until later, and two were women with haematuria, with relatives with poor renal function and ocular signs.

Our clinical impression is that Alport variant males develop renal failure at a later age than those with the typical syndrome. The fact that none of our Alport variant patients showed ocular signs supports the suggestion that ocular signs (as well as deafness) are associated with a poorer prognosis.

The incidence of ocular signs in our series is lower than in other series. ${ }^{5,6}$ This probably reflects the fact that fewer of our patients had poor renal function (21.4 per cent in our series; 62.5 per cent in Perrin et al; 60 per cent in Gubler et al.).
Ocular signs and the inheritance of Alport's syndrome

The inheritance of Alport's syndrome is disputed. Kindreds which show autosomal dominant, autosomal recessive and $\mathrm{X}$-linked dominant patterns have all been described. ${ }^{17,18,19}$ It seems most likely to be a genetically heterogeneous condition. ${ }^{20}$ Our data seem to support an X-linked inheritance in many cases, but this will be the subject of further study.

We examined the eyes of many patients' relatives to see whether apparently unaffected members of Alport's families could show ocular signs in isolation. None were found. Some Alport's kindreds contain individuals with isolated sensorineural deafness, ${ }^{21}$ and this can help in the diagnosis of the syndrome. However, the same is not true of ocular signs.

\section{Conclusion}

People with Alport's syndrome sometimes have characteristic ocular changes. Further useful information will come from examining more young children with the syndrome, from continuing follow-up of these families, and from ultrastructural and biochemical studies of the eyes of affected individuals.

We thank Richard Hildred for preparing the figures, Kent Woods for statistical assistance, and the staff of the Orthoptic Department, Children's Hospital, Birmingham, for their willing help.

\section{References}

${ }^{1}$ Spear GS and Slusser RJ: Alport's syndrome: emphasizing electron microscopic studies of the glomerulus. Am. J. Pathol. 1972, 69: 213.

2 Yoshikawa N, Cameron AH and White RHR: The glomerular basal lamina in hereditary nephritis. Br. J. Pathol. 1981, 135: 199-209.

${ }^{3}$ Yoshikawa N, White RHR and Cameron AH: Familial haematuria: clinico-pathological correlations. Clin. Nephrol. 1982, 17: 172-82.

${ }^{4}$ Faggioni R, Scouras J and Streiff EB: Alport's syndrome: clinicopathological considerations. Ophthalmologica 1972, 165: 1-14.

${ }^{5}$ Perrin D, Jungers P, Grunefeld JP, Delons S, Noel L-H and Zenatti C: Perimacular changes in Alport's syndrome. Clin. Nephrol. 1980, 13: 163-7.

${ }^{6}$ Gubler M, Levy M, Broyer M, Naizot C, Gonzales G, Perrin D and Habib R: Alport's syndrome. A report of 58 cases and a review of the literature. Am. J. Med. 1981, 70: 493-505. 
7 Sabates R, Krachmer JH and Weingeist TA: Ocular findings in Alport's syndrome. Ophthalmologica 1983, 186: 204-210.

${ }^{8}$ Polak BCP and Hogewind BL: Macular lesions in Alport's disease. Am. J. Ophthalmol. 1977, 84: 532-5.

${ }^{9}$ Sohar E: Renal disease, inner ear deafness, and ocular changes. Arch. Intern. Med. 1956, 97: 627-30.

${ }^{10}$ Davies PD: Pigment dispersion in a case of Alport's syndrome. Br. J. Ophthalmol. 1970, 54: 557-61.

${ }^{11}$ Govan JAA: Ocular manifestations of Alport's syndrome: a hereditary disorder of basement membranes? Br. J. Ophthalmol. 1983, 67: 493-503.

${ }^{12}$ Tripathi RC, Casey TA and Wise G: Hereditary posterior polymorphous dystrophy, an ultrastructural and clinical report. Trans. Ophthalmol. Soc. UK 1974, 94: 211-25.

${ }^{13}$ Brownell RD and Wolter JR: Anterior lenticonus in familial hemorrhagic nephritis. Arch. Ophthalmol. 1964, 71: 481-3.

${ }^{14}$ Peterson WS and Albert DM: Fundus changes in the hereditary nephropathies. Trans. Am. Acad. Ophthal. Otolaryngol. 1974, 78: 762-71.
15 Spear GS: Hereditary nephritis (Alport's syndrome)-1983. Clin. Nephrol. 1984, 21: 3-6.

${ }^{16}$ Dibona GF: Alport's syndrome: a genetic defect in biochemical composition of basement membrane of glomerulus, lens and inner ear? J. Lab. and Clin. Med. 1983, 101: 817-20.

${ }^{17}$ Perkoff GT, Nugent CA, Dolowitz DA, Stephens FE, Carnes WH and Tyler FH: A follow-up study of hereditary chronic nephritis. Arch. Intern. Med. 1958, 102: 733-46.

${ }^{18}$ Feingold J, Bois E, Chompret A, Broyer M, Gubler M-C and Grunfeld J-P: Genetic heterogeneity of Alport syndrome. Kid. Internat. 1985, 27: 672-7.

${ }^{19}$ Hasstedt SJ and Atkin CL: X-linked inheritance of Alport syndrome: family $\mathrm{P}$ revisited. Am. J. Hum. Genet. 1983, 35: 1241-51.

${ }^{20}$ Evans SH, Erickson RP, Kelsch R and Peirce JC: Apparently changing patterns of inheritance in Alport's hereditary nephritis: genetic heterogeneity versus altered diagnostic criteria. Clin. Genet. 1980, 17: 285-92.

${ }^{21}$ Cohen MM, Cassady G and Hanna BL: A genetic study of hereditary renal dysfunction with associated nerve deafness. Am. J. Hum. Genet. 1961, 13: $379-89$. 